\title{
FOURIER LANDSCAPE PATTERN INDICES FOR PREDICTING SOUTH CAROLINA WATERSHED FECAL COLIFORM
}

\author{
ALVIN SPIVEY AND ANTHONY VODACEK \\ Rochester Institute of Technology, 54 Lomb Memorial Drive, Rochester, NY 14623
}

Received: $16^{\text {th }}$ December 2016, Accepted: $5^{\text {th }}$ April 2017

\begin{abstract}
Extending the Landscape Pattern Metric (LPM) model analysis in Smith et al. (2001) into a LPM decision model, decadal scale prediction of fecal coliform compromised South Carolina watersheds is developed. The model's parameter variability identifies the greatest contributors to a compromised watershed's prediction. The complete set of model parameters include Land Cover Land Use (LCLU) \& slope, along stream proportion, Fourier Metric of Fragmentation $(F M F)$, Fourier Metric of Proportion $(F M P)$, and Least Squares Fourier Transform Fractal Dimension (LsFT). The 1992 National Land Cover Data (NLCD) Land Cover Land Use (LCLU) within fecal coliform compromised watersheds is used to train the model parameters, and the 2001 NLCD LCLU is used to test the LPM model. The most significant model parameters are along stream bare rock LsFT, FMF between urban/recreational grasses and evergreen forests, and FMF between deciduous forests and high density residential areas. These metrics contribute significantly more than the best proportion descriptor: proportion of urban/recreational grasses. In training, the proposed model correctly identified $92 \%$ of the compromised watersheds; while the Smith et al. (2001) model $94 \%$ of the compromised watersheds were correctly identified. This study reveals the ability of Fourier metrics to interpret ecological processes, and the need for more appropriate landscape level models.
\end{abstract}

Keywords: Landscape Pattern Metrics, Fourier, South Carolina, Watershed, Fecal Coliform, Landscape Model.

\section{INTRODUCTION}

The Land Use appropriation of States, territories and tribal lands have altered hydrologic connectivity between landscapes, groundwater, and streams. This has led to more efficient delivery of contaminants to receiving waters through nonpoint source pollutants. Additionally, loss of natural headwater streams and floodplain wetlands associated with Land Cover Land Use (LCLU) change decreases retention capacity, increases erosion, and may further contribute to nonpoint source contaminants downstream (Kaushal et al., 2010).

To prevent aggressive loads of nonpoint source pollutants into local waters, water quality evaluations are completed biennially under section 305 of the Clean Water Act (CWA). Part of this evaluation includes identification, listing and prioritizing of water bodies that do not meet the water quality standards. This list of compromised water bodies is referred to as the 303(d) list. Under the Clean Water Act, States and jurisdictions are required to develop Total 
Maximum Daily Loads (TMDL) for the water bodies on the 303(d) list to prevent other water bodies from becoming compromised.

Smith et al. (2001) reports on LPM for a majority ( 65\%) of the South Carolina sites placed on the 303(d) list due to levels of fecal coliform. These high concentrations of fecal coliform are indicative of pollution that cannot be tracked to effluent emanating from a pipe, discharging into the water body. The Landscape Pattern Metrics (LPM) of Smith et al. (2001) indicate watershed LCLU characteristics as a contributor to South Carolina's nonpoint source fecal coliform problem - particularly for watersheds with large proportions of urban Land Cover and agriculture on steep slopes (> $9 \%$ ) (Jennings et al., 2004; Jones et al., 2001, Smith et al., 2001; Vogelmann et al., 2001; Wickham et al., 2000). However, their work did not identify which watersheds suffered from these LCLU characteristics.

The analysis shown here extends the work done by Smith et al. (2001), using updated watershed delineations from the National Hydrography Dataset (NHD) (NHD, 2009), the 303(d) list (SCD, 2009) for 1992 and 2001, U.S. Multi-Resolution Land Characteristics Consortium (MRLC) National Land Cover Data (NLCD) (MRL, 2009), and a set of proportion LPM. The aim of this study is to present the proposed composition and connectivity Fourier Landscape Pattern Metrics' factor analysis, revealing their abilities as Indicators of Fecal Coliform loads. This information is used in landscape level models to predict which watersheds may be compromised in the future.

\section{DATA}

There are multiple Geographic Information System (GIS) data layers used to identify and create LPM that are aware of geographic detail, political boundaries, chemical variables, and anthropogenic effects. All of these data are overlaid across Land Cover Land Use (LCLU) products using the CWA fecal coliform census, and recent 14-digit NHD stream and watershed delineations.

\section{National Land Cover Data}

1992 and 2001 National Land Cover Data (NLCD) are a 21-category LCLU classification scheme (see Table 1) and a 19-category LCLU classification scheme (see Table 2). Outside of the differences between the number of categories from 1992 to 2001, the LCLU classification schemes are equivalent. The map is based primarily on the unsupervised classification of Landsat TM 1992 imagery. Ancillary data sources include topography, census, agricultural statistics, soil characteristics, other land cover maps, and wetland data. The NLCD classification is raster data with spatial resolution $30(\mathrm{~m})$. The seamless product is cast to the Albers Equal-Area conic projection, references to the North American Datum of 1983 (NAD83).

An example of NLCD LCLU products for Columbia, SC in 1992 and 2001 are shown in Figure 1. Class descriptions and codes from NLCD 1992 and NLCD 2001 are derived from components of the Anderson Level I and II (Anderson et al, 1976) and National Oceanic and Atmospheric Administration (NOAA) Coastal Change and Analysis Program (C-CAP) Land Cover classes (MRL, 2010). The accuracy between 1992 and 2001 data have not been settled, however the increased 2001 NLCD LCLU details is most obvious along streams, like in Figure 1. 
Spivey A., Vodacek A.: Fourier Landscape Pattern Indices for Predicting South Carolina Watershed Fecal Coliform

Table 1: Descriptions of LCLU attributes class codes for 1992 NLCD (Anderson et al., 1976)

\begin{tabular}{ll}
\hline \hline LCLU class code & Anderson Level II attribute class description \\
\hline 11 & Open Water \\
12 & Perennial Ice/Snow \\
21 & Low Intensity Residential \\
22 & High Intensity Residential \\
23 & Commercial, Industrial, Transportation \\
31 & Bare Rock, Sand \\
32 & Quarry, Strip Mine, Gravel Pits \\
33 & Transitional Barren \\
41 & Deciduous Forest \\
42 & Evergreen Forest \\
43 & Mixed Forest \\
51 & Shrubland \\
61 & Orchards, Vineyards, Other \\
71 & Grassy, Herbaceous \\
81 & Pasture, Hay \\
82 & Row Crops \\
83 & Small Grains \\
84 & Fallow \\
85 & Urban, Recreational Grasses \\
91 & Woody Wetlands \\
92 & Emergent Herbaceous Wetlands \\
\hline
\end{tabular}

To maintain LPM model precision between 1992 and 2001, all datasets are registered to the same general LCLU code used by Smith et al. (2001). The LCLU codes include: urban (11, $21,22,23,31,32,33)$, natural vegetation $(41,42,43,52,71,90,91,92,95)$, and agriculture $(81,82,85)$. Statistical analysis and interpretation is done for the full 1992 LCLU code in Table 1. It is only when LPM are incorporated into the model that the general urban, vegetation, and agriculture codes from Smith et al. (2001) are used.

\section{National Hydrography Dataset}

Digital coverage of the 2001 14-digit hydrologic unit code (HUC) watersheds were obtained from the South Carolina Department of Health and Environmental Control (DHEC). They are 1,032 watersheds that range in size from 4.5 to $226\left(\mathrm{~km}^{2}\right)$. These watersheds are clipped to the SC border, with those watersheds on the South Carolina-to-North Carolina border not delineated by interfluves removed. For context, Figure 2 overlays the South Carolina Hydrologic Unit Map across the Georgia-Carolina political boundaries. The 14-digit HUC NHD is cast to the Albers Equal-Area Conic projection, referenced to NAD83, and rasterized using a cell size of $30(\mathrm{~m})$. 
The 1992 and 2001 SC 303(d) list

Which watersheds were compromised by fecal coliform in 1992 and 2001 were obtained from the SC DHEC archived 303(d) lists. Two sampling strategies were employed in gathering the water quality data. Primary test points, established near high-use waters, are tested every month throughout the year; while secondary points, located near areas with a history of impairment problems, are tested for six months of the year during the summer. A map of the 2001 303(d) list fecal coliform compromised watersheds is shown in Figure 3. Out of the total 1,032 watersheds, 471 (46\%) were compromised in 1992 and $436(42 \%)$ in 2001.

Table 2: Descriptions of LCLU attributes class codes for 2001 NLCD (Anderson et al., 1976), and the retrofitted 1992 codes

\begin{tabular}{ll}
\hline \hline LCLU class code (1992 retrofit) & Anderson Level II attribute class description \\
\hline 11 & Open Water \\
12 & Perennial Ice/Snow \\
$21(85)$ & Developed, Open Space \\
22 & Developed, Low Intensity \\
23 & Developed, Medium Intensity \\
24 & Developed, High Intensity \\
$31(32,33)$ & Barren Land, Rock, Sand, Clay \\
32 & Unconsolidated Shore in Coastal Areas \\
41 & Deciduous Forest \\
42 & Evergreen Forest \\
43 & Mixed Forest \\
$52(51)$ & Shrub, Scrub \\
71 & Grassy, Herbaceous \\
81 & Pasture, Hay \\
$82(83,84)$ & Cultivated Crops \\
$90(91)$ & Woody Wetlands \\
91 & Palustrine Forested Wetland in Coastal Areas Only \\
92 & Palustrine Scrub/Shrub Wetland in Coastal Areas Only \\
$95(92)$ & Emergent Herbaceous Wetlands \\
\hline
\end{tabular}

\section{METHODS}

While the CWA fecal coliform census provide measurements of which watersheds are compromised by fecal coliform, descriptions of fecal coliform transport through LCLU have not been measured. These descriptions of the rate at which fecal coliform transports through LCLU are referred to as export coefficients. When export coefficients are multiplied against the coverages area of LCLU, that product allows LCLU to act as a proxy for nutrient load. For reliable fecal coliform predication, nonpoint source fecal coliform export coefficient measurements are substituted by historical nitrogen load export coefficients. Why nitrogen export coefficients can be substituted for fecal coliform export coefficients is discussed 
Spivey A., Vodacek A.: Fourier Landscape Pattern Indices for Predicting South Carolina Watershed Fecal Coliform

below. Each of these assembled data layers, the base map's configuration, and how the LPM are interpreted are explained below as well.

\section{Modified Beaulac and Reckhow (1982) LPM model}

Nutrient export coefficients are the flow rates multiplied by the amount (area) of a given LCLU type. When modeling the likelihood of increased nutrient loads due to difference in land-cover composition, broad LCLU categories (i.e. urban, natural vegetation, and agriculture) can be reliably used as watershed level Indicators of nutrient load (Vogelmann et al., 1998a,b; Zhu et. al., 2000).

Fig. 1: A chip of the National Land Cover Database (NLCD) Columbia, SC in 1992 and 2001

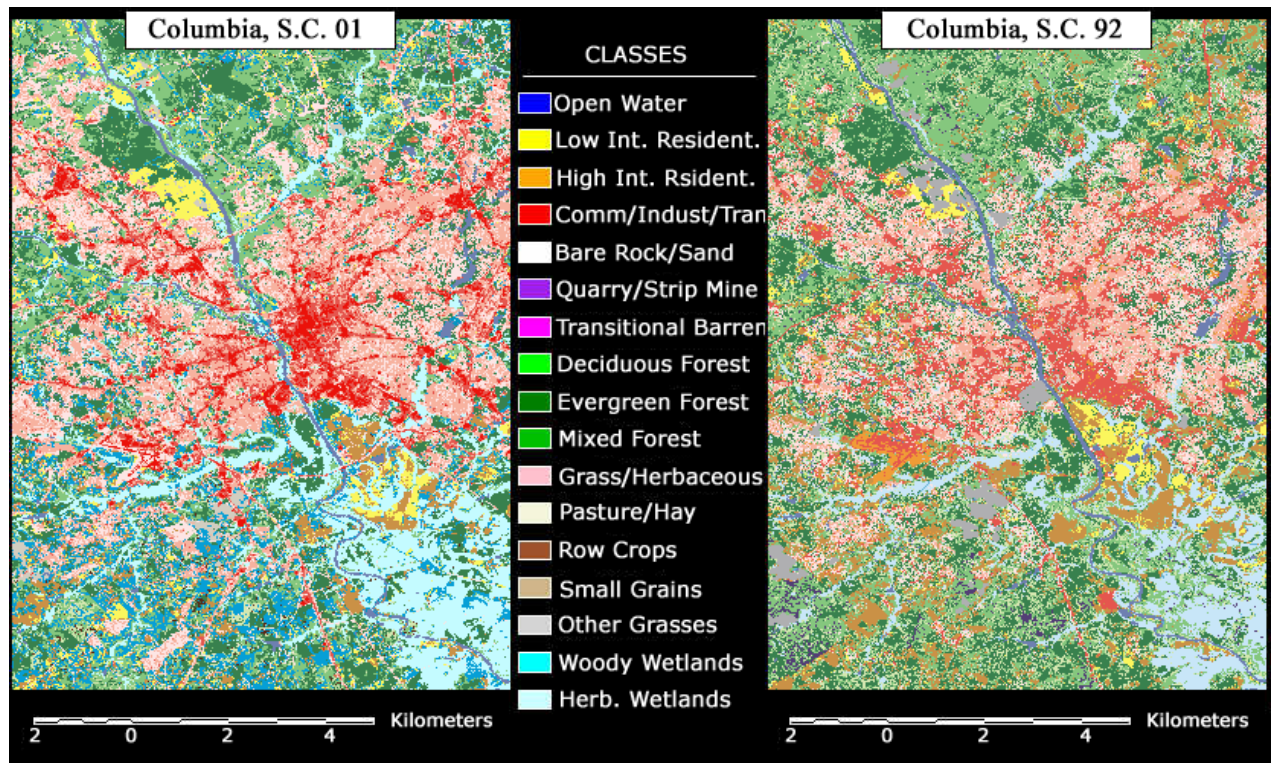


Fig. 2: A map of the South Carolina Hydrologic Unit Map in 2001. The South Carolina Basin is shown in white, while watershed regions shown in a transparent blue across political boundaries have not been clipped

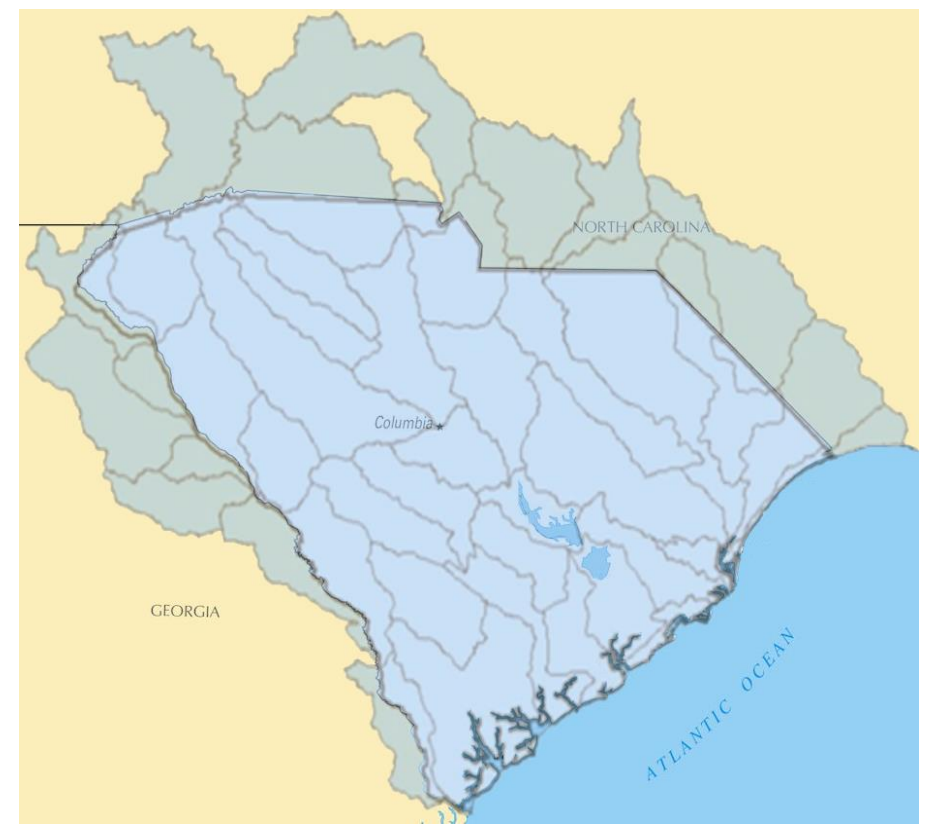

Fig. 3: A map of SC watersheds that were compromised in 2001. The watersheds compromised are shown as black, while areas not effected by inordinate fecal coliform loadings are shown as pink

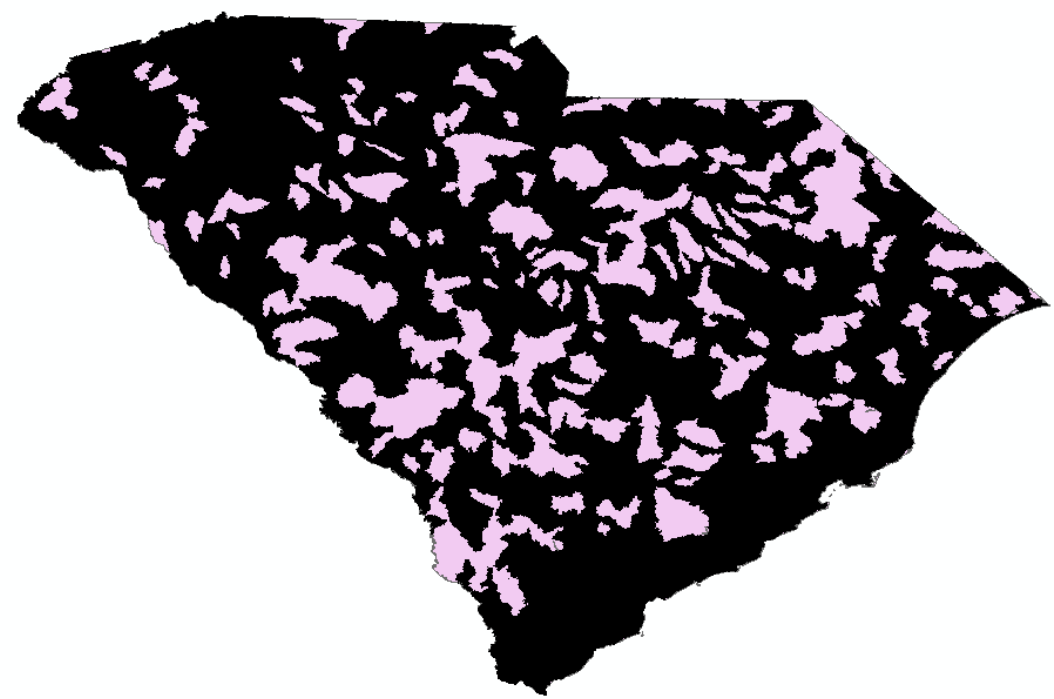


Spivey A., Vodacek A.: Fourier Landscape Pattern Indices for Predicting South Carolina Watershed Fecal Coliform

The modified Beaulac \& Reckhow (1982) LPM model developed here identifies potential fecal coliform compromised watersheds due to an increase in fecal coliform nutrient loads. Baulac \& Reckhow (1982) originally used parameters of LCLU composition within a watershed, to model nitrogen and phosphorus loads as:

$$
N, P=\sum_{i}^{n} c_{i} \cdot A_{i}
$$

$N$ and $P$ loads are estimated as the product of the area $A$ of LCLU type $i$ and its export coefficient $c_{i}$ as summed across all $n$ LCLU types in the watershed.

This equation can be used in two ways. If areal estimates are known for the different LCLU types, Equation 1 would provide a weighted average estimate of nutrient load for the entire State of SC. In this case $N$ and $P$ units would be in kilograms per year $\left[\frac{\mathrm{Kg}}{\mathrm{yr}}\right]$. Alternatively, LCLU types could be expressed as a proportion of watershed level LCLU types like in Equation 2. Equation 2 provides a weighted average estimate of $N$ and $P$ nutrient export coefficients, $\hat{c}_{N}$ and $\hat{c}_{P}$. Now, the Statewide contribution of individual SC watersheds can be compared in units of kilograms per hectare per year $\left[\frac{\mathrm{Kg}}{\mathrm{ha} \cdot \mathrm{yr}}\right]$ :

$$
\hat{c}_{N}, \hat{c}_{P}=\sum_{i}^{n} c_{i} \cdot A \cdot p_{i}
$$

Equation 2 was used in the analysis of likely causes of Fecal Coliform loads done by Smith et al, (2001).

\section{Average-Based Model}

By modifying equation 2, how connected LCLU are within watersheds can be included. Taking the average of the $M$ proposed LCLU Fourier metrics (i.e. FMP, FMF, and $L s F T$ ) as $m_{i}$, and modulating the proportion metric by $m_{i}$, Equation 3 includes an expression for connectivity into the increased nutrient load prediction model:

$$
\hat{c}_{N}, \hat{c}_{P}=\sum_{i}^{n} c_{i} \cdot A \cdot p_{i} \cdot m_{i}=\sum_{i}^{n} c_{i} \cdot A \cdot p_{i} \cdot \frac{\sum_{j}^{M} m_{i j}}{M} .
$$

This model applies equal emphasis on each type of watershed sub-basin LCLU pattern by averaging the proposed connectivity Fourier LPM into a connectivity modulation parameter $m_{i j}$.

Vector-Based Model

Instead of using the model in Equation 3, we can use models that emphasize different types of connected LCLU relationships. This can be done by way of the vector product between a unit reference vector $\widetilde{\boldsymbol{u}}$ whose values are all $\mathbf{1}$, and the LPM vector $\widetilde{\boldsymbol{v}} \equiv\left(m_{i j}\right)$ whose values are every $j$ watershed sub-basin landscape Indicator for one of the $i=3$ watershed sub-basin's aggregate LCLU (i.e. urban, natural vegetation or agricultural):

$$
\tilde{v} \cdot \tilde{u} .
$$

The unit reference vector and the LPM vector are the same if the LPM vector is composed of all ones. This vector would be the LPM response for a landscape that is compact if $F M F=1$, well connected from $F M P=1$, and evenly grouped from $L s F T=1$. Comparing the 
LPM vector for how similar it is to this LCLU extreme is mathematically expressed as the similarity between the two vectors, or the vector dot product:

$$
\cos [\theta]=\frac{(\widetilde{\boldsymbol{v}} \cdot \widetilde{\boldsymbol{u}})}{|\widetilde{v}||\widetilde{u}|^{*}}
$$

Equation 5 is a LCLU similarity-based model.

Conversely, comparing the LPM unit vector to how dissimilar it is to this LCLU extreme is mathematically expressed as the dissimilarity between the two vectors, or the vector cross product:

$$
\sin [\theta]=\frac{|\widetilde{v} \times \widetilde{u}|}{|\widetilde{v}||\widetilde{u}|}=\frac{\sqrt{|\widetilde{v} \times \widetilde{u}|^{2}}}{|\widetilde{v}||\widetilde{u}|}=\frac{\sqrt{|\widetilde{v}|^{2}|\widetilde{u}|^{2}-(\widetilde{v} \cdot \widetilde{u})^{2}}}{|\widetilde{v}||\widetilde{u}|} .
$$

Equation 6 is a LCLU dissimilarity-based model. A high measure of dissimilarity from Equation 6 would indicate a landscape cover that is sparse, not very diverse and lay in no structured pattern. Using the original model parameters from Equation 3, expressions for LCLU similarity and dissimilarity look very close to the average-based model:

$$
\begin{aligned}
& \cos [\theta]=\frac{\sum_{j}^{M} m_{i j}}{\sqrt{m_{i j} M}} \Rightarrow \hat{c}_{N}^{\prime}, \hat{c}_{P}^{\prime}=\sum_{i}^{n} c_{i} \cdot A \cdot p_{i} \cdot \frac{\sum_{j}^{M} m_{i j}}{\sqrt{m_{i j} M}} ; \\
& \sin [\theta]=\frac{\sum_{j}^{M} \sqrt{m_{i j} M-m_{i j}^{2}}}{\sqrt{m_{i j} M}} \Rightarrow \hat{c}_{N}^{\prime \prime}, \hat{c}_{P}^{\prime \prime}=\sum_{i}^{n} c_{i} \cdot A \cdot p_{i} \cdot \frac{\sum_{j}^{M} \sqrt{m_{i j} M-m_{i j}^{2}}}{\sqrt{m_{i j} M}} .
\end{aligned}
$$

\section{Model Interpretation}

The best $m_{i}$ modulation model would vary the existing LCLU proportion $p_{i}$ to more accurately predict potentially compromised watersheds. The $m_{i}$ modulation model that increases decision accuracy also provides an interpretation for the cause of nonpoint source fecal coliform loads. Possible model interpretations include: the average-based Equation 3 assumption that any measured connection between LCLU describes nutrient transport in general; the similarity-based Equation 7 assumption that LCLU must be compact, well connected, and evenly grouped to best describe nutrient transport; and the dissimilarity-based Equation 8 assumption that LCLU must be sparse, not very diverse, and lay in no structured pattern to best describe nutrient transport.

To complete the analysis and best describe nutrient transport, the export coefficient parameter $c_{i}$ for fecal coliform is necessary, but fecal coliform export coefficients across urban, natural vegetation, and agriculture SC LCLU have not been developed. So instead, well documented nutrient export coefficients for nitrogen loadings are used as a substitute.

\section{Fecal Coliform Export Coefficients}

Fecal coliform is the bacteria that usually reside in the digestive tract of warm blooded animals, and is used in nutrient transport experiments to understand the presence of pathogens in water bodies. Similarly, sources of anthropogenic nitrogen to streams include sewage, animal wastes, fertilizers, and natural sources such as organic matter. Levels of nitrogen can be used to indicate the impact of human settlements and Land Use on the natural environment, provided natural sources of nitrogen (i.e. dried blood, poultry waste, fish remains, seabird droppings, bat droppings, corn glutton, acid rain and more of the same (Dorn, 2011)) can be assumed to be negligible. These alternative nitrogen export coefficients 
Spivey A., Vodacek A.: Fourier Landscape Pattern Indices for Predicting South Carolina Watershed Fecal Coliform

become an increasingly better substitution for fecal coliform export coefficients as nitrate contamination of groundwater increases, like that found around some rural-residential areas (Sta, 2010). This study's SC watersheds are mostly composed of rural-residential Land Use, so anthropogenic nitrogen export coefficients are an appropriate substitution for fecal coliform export coefficients in SC watersheds.

The export coefficients used here are shown in Table 3. These export coefficients indicate the potential LCLU annual nitrogen load in kilograms, across one hectare. When used for areal loads in the LPM model (see equation 3 and the discussion in section 2.1), three LCLU aggregates are taken as relevant export coefficient LCLU averages: urban $\left(450\left[\frac{\mathrm{Kg}}{\mathrm{ha} \cdot \mathrm{yr}}\right]\right)$, natural vegetation $\left(173.4\left[\frac{\mathrm{Kg}}{\mathrm{ha} \cdot \mathrm{yr}}\right]\right)$, and agriculture $\left(610\left[\frac{\mathrm{Kg}}{\mathrm{ha} \cdot \mathrm{yr}}\right]\right)$.

The allowed SC DHEC watershed nitrogen load is $\frac{200}{100}\left[\frac{c f u}{m l}\right]$ - where the units $\left[\frac{c f u}{m l}\right]$ are colony forming units per milliliter (S.C. DHEC, 2008). Using the SC DHEC typical watershed gallons per minute flow rate, this $\frac{200}{100}\left[\frac{\mathrm{cfu}}{\mathrm{ml}}\right]$ limit can be expressed as $2986\left[\frac{\mathrm{Kg}}{\mathrm{yr}}\right]$. This typical watershed annual limit, in units of $\left[\frac{\mathrm{kg}}{\mathrm{yr}}\right]$ is compared to the predicted LPM model potential loads, in units of $\left[\frac{\mathrm{Kg}}{\mathrm{yr}}\right]$ and is the threshold used to determine whether a watershed is compromised.

Table 3: Descriptions of LCLU the nitrogen export coefficients from Jeje (2006)

\begin{tabular}{llc}
\hline \hline 2001 LCLU class code & Description & c $_{\mathrm{N}}{ }^{\mathrm{a}}$ \\
\hline 21 & Urban & 5.50 (Reckhow et al., 1980) \\
22 & Urban, Residential & 6.15 (Reckhow et al., 1980) \\
$23(24)$ & Industrial & 2.25 (Reckhow et al., 1980) \\
31 & Subalpine & 3.75 (Bondelid et al. 2001) \\
32 & Strip mines/barren land & 8.60 (Group, 1998) \\
33 & Mostly urban & 0.79 (USEPA, 1976) \\
41 & Forest & 2.50 (USEPA, 1976) \\
42 & Forest & 2.50 (USEPA, 1976) \\
$43(52,71)$ & Forest & 2.46 (Reckhow et al., 1980) \\
81 & Pasture & 5.10 (MDEQ, 2001) \\
82 & Row Crops & 8.20 (MDEQ, 2001) \\
85 & Urban & 5.00 (USEPA, 1976) \\
$91(90)$ & Watershed wetlands & 0.55 (Group, 1998) \\
$92(95)$ & Watershed agricultural basin & 0.60 (Jeje, 2006) \\
\hline
\end{tabular}

${ }^{\mathrm{a}}$ Nitrogen export coefficient in units of $\left[\frac{\mathrm{Kg}}{\mathrm{ha} \cdot \mathrm{yr}}\right]$.

\section{Factor Analysis}

The approach to factor analysis is the same as was discussed in Spivey \& Vodacek (2017). However, here the correlation matrix $\hat{\Sigma}$ is populated with LPM values from each of the $t$ watersheds, that reveal the observed metric's ability to explain compromised watersheds. The $\Psi$ diagonal terms are now the LPM's potential to predict fecal coliform loadings. So, the more contribution to independent fecal coliform descriptions $\bar{\sigma}_{j}$ a LPM tends to make, the more uniquely able to describe fecal coliform the LPM is - this allows us to say to what degree the observed metric and fecal coliform are unrelated.

In this factor analysis, a direct measure of LPM ability to explain the $p$ observed LCLU watershed changes compared to the full set of metrics (i.e. LCLU \% slope, along stream 
proportion, FMF , FMP , and $L s F T$ ) is obtained. The LPM that contributed most to explained variance are along stream bare rock LsFT (with $99.33 \%$ expected contribution to explained variance), FMF between urban/recreational grasses and evergreen forests (with $99.32 \%$ expected contribution to explained variance), and FMF between deciduous forests and high density residential areas (with $98.66 \%$ expected contribution to explained variance). These metrics contribute significantly more than the best proportion descriptor: proportion of urban/recreational grasses (having $45.12 \%$ expected contribution to explained variance). The Spivey \& Vodacek (2017) Equation used for these estimates is shown below:

$$
\bar{\sigma}_{j}=\frac{\Psi_{j, j}}{\sigma_{j, j}} .
$$

After the LPM model parameters have been trained on the SC 1992 LCLU watersheds, how effective the model is to predict compromised watersheds is determined by applying the model to SC 2001 LCLU watersheds. The measure of success is the 1992 trained model's ability to identify 2001 's fecal coliform compromised watersheds.

\section{ANALYSIS}

Fig. 4: LPM model parameters that typically contribute greater than $50 \%$ to the explained compromised watershed LCLU variability. These LPM parameters are all Fourier based and ranked from left-to-right as most-to-least significant

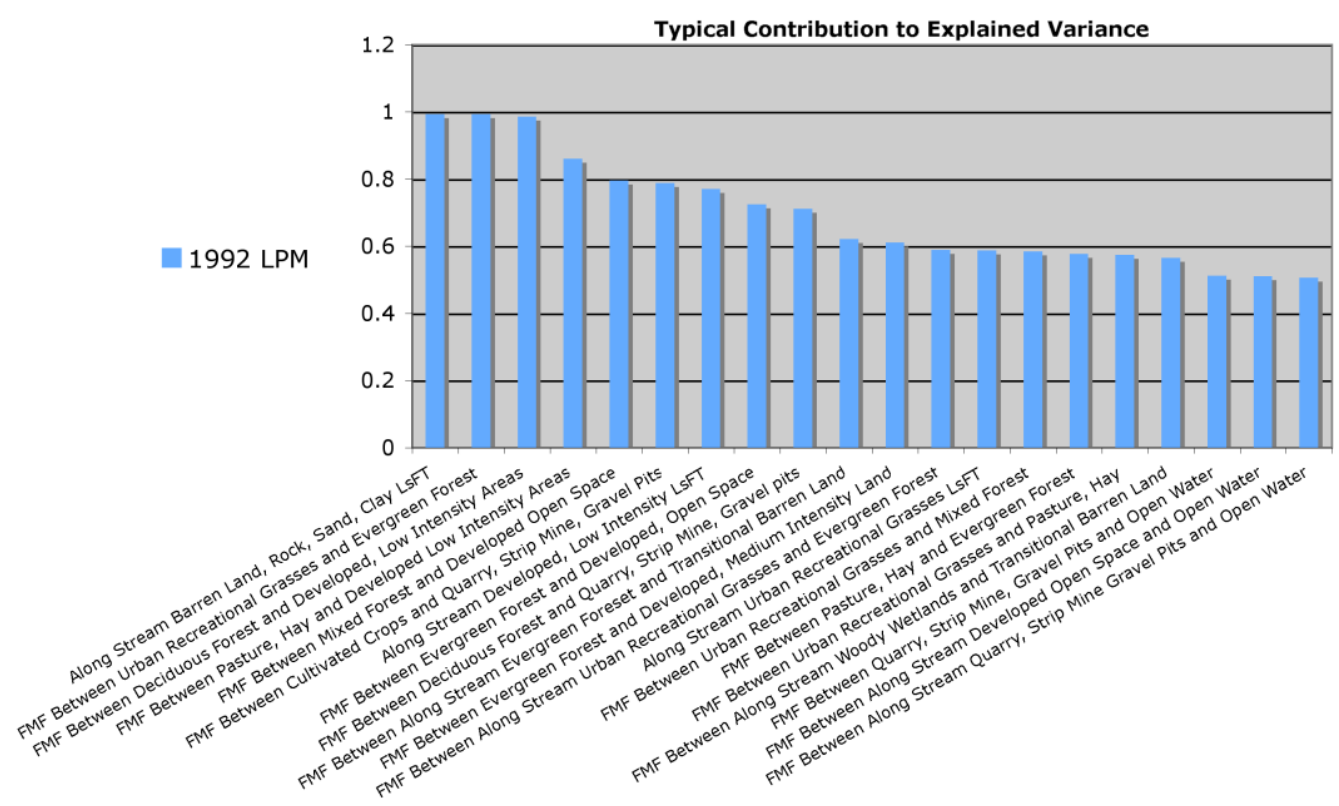

304 parameters are used in the 1992 LPM training model, of which only 19 typically contribute to greater than $50 \%$ of the explained compromised watershed LCLU variability. Only these 19 LPM and their contribution are considered as relevant, having contributed to greater than $50 \%$ of the 1992 explained compromised watershed LCLU variability, and are shown in Figure 4. Each of the model parameters determined to be relevant at a $>50 \%$ significance level for proposed Fourier metrics. The proportion LPM used by Smith et al., 
Spivey A., Vodacek A.: Fourier Landscape Pattern Indices for Predicting South Carolina Watershed Fecal Coliform

(2001) have typical contributions shown in Figure 5, which correspond to the proportion LPM published in their general prediction results. However, these proportion LPM are relatively less significant than the proposed Fourier metrics.

Fig. 5: LPM model parameters of Smith et al., (2001) proportion. These LPM parameters are separated between within-watershed proportion (blue) and along-stream proportion (red). They are also based and ranked from left-to-right as most-to-least significant

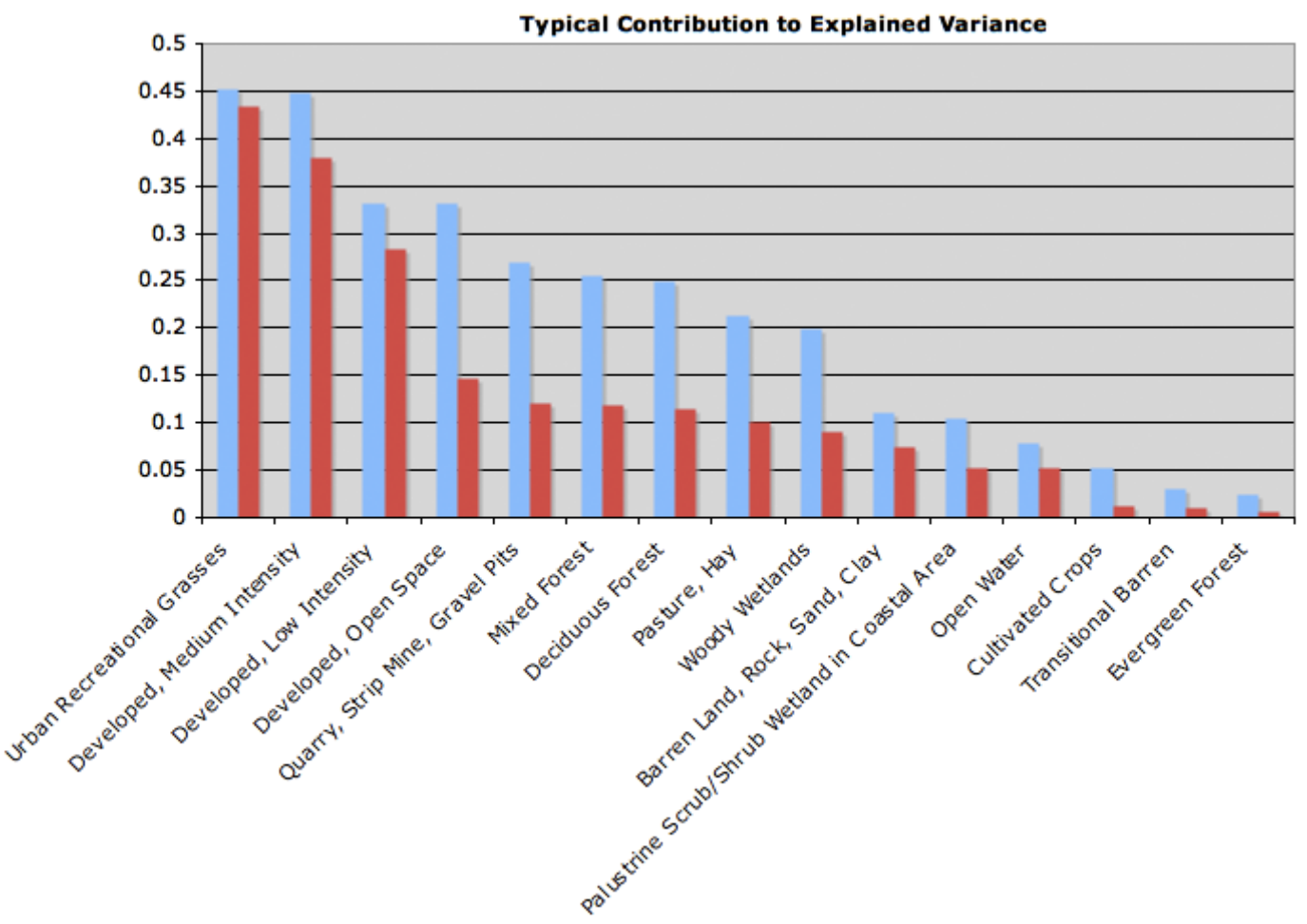

Using the average-based Beaulac \& Reckhow (1982) model in equation 3, and the generalized LCLU export coefficients, the 1992 model is trained with a $91.72 \%$ accuracy. The 1992 average-based LPM model identified 432 out of 471 fecal coliform compromised watersheds. Using the original Beaulac and Reckhow (1982) model, as was used by Smith et al. (2001) (see equation 2), the 1992 LCLU prediction accuracy increases to $93.63 \%$-identifying 441 out of the 471 fecal coliform compromised watersheds. When applied to the 436 compromised watersheds in 2001 the average-based LPM model identified $81.42 \%$ (355 out of 436) of the fecal coliform compromised watersheds. Both of the vector-based models performed near the same level or better than the original Beaulac et al. (1982) model, in training and testing data results. A summary of these model performances and the other modified model predictions are shown in Table 4. 
Table 4: Landscape Indicator Model Fecal Coliform Load Prediction

\begin{tabular}{l|l|l} 
& 1992 Training Data Results & 2001 Testing Data Results \\
\hline Smith et al., (2001) Model & $93.63 \%$ & $91.51 \%$ \\
Average-Based Model & $91.72 \%$ & $81.42 \%$ \\
Similarity-Based Model & $93.64 \%$ & $89.22 \%$ \\
Dissimilarity-Based Model & $99.36 \%$ & $98.62 \%$ \\
\hline
\end{tabular}

\section{SUMMARY OF THE RELEVANCE OF FOURIER LANDSCAPE PATTERN INDICATORS TO PREDICT FECAL COLIFORM}

The predicted loads for every compromised watershed in 2001 is shown in Figure 6. Figure 6 shows watershed load predictions from the Smith et al. (2001) model and the average-based LCLU models. From left to right, the first loads are those where the models disagreed and the later loads are those where the models agreed-the difference between these two is clearly marked by the spiked increase in potential annual nitrogen load. The effects of modulating the Smith et al. (2001) model by $m_{i}$ in equation 3 are to only decrease the potential annual load prediction. This is the effect seen in each vector-based method. No effective variability is introduced by using either of these model modifications, though detection accuracy was increased for the vector-based methods, particularly for the dissimilarity-based method. The gains in prediction were obtained by increasing every predicted watershed load by the same multiplicative constant $m_{i}$, pushing the most extreme predictions slightly above the previous Smith et al. (2001) model predictions. However, the dissimilarity-based model's performance leads to the interpretation that the type of LCLU connectivity that best explains watershed level, nonpoint source, fecal coliform transport is sparse, not very diverse, and lay in no structured pattern.

Those proportion LPM identified by Smith et al. (2001) explain the watershed level landscape variability relatively less than the connectivity, Fourier based LPM being proposed. Still though, the order of the type of LCLU that best Indicated the presence of Fecal Coliform was the same (see Figure 5). These 19 connectivity LPM parameter's ability to explain more variability suggests their increased ability to predict nutrient loads. Because the connectivity LPM modified models only decreased or increased predicted loads from the Smith et al. (2001) proportion LPM model by a multiplicative factor, the likely prediction advantage suggested by the connectivity LPM \% explained variability may not have been fully exploited by the models developed here. This suggests that more model development is needed to produce models that leverage the connectivity LPM discriminability. 
Spivey A., Vodacek A.: Fourier Landscape Pattern Indices for Predicting South Carolina Watershed Fecal Coliform

Fig. 6: Potential nitrogen load predictions of the Smith et al. (2001) model and the modified average-based model presented here

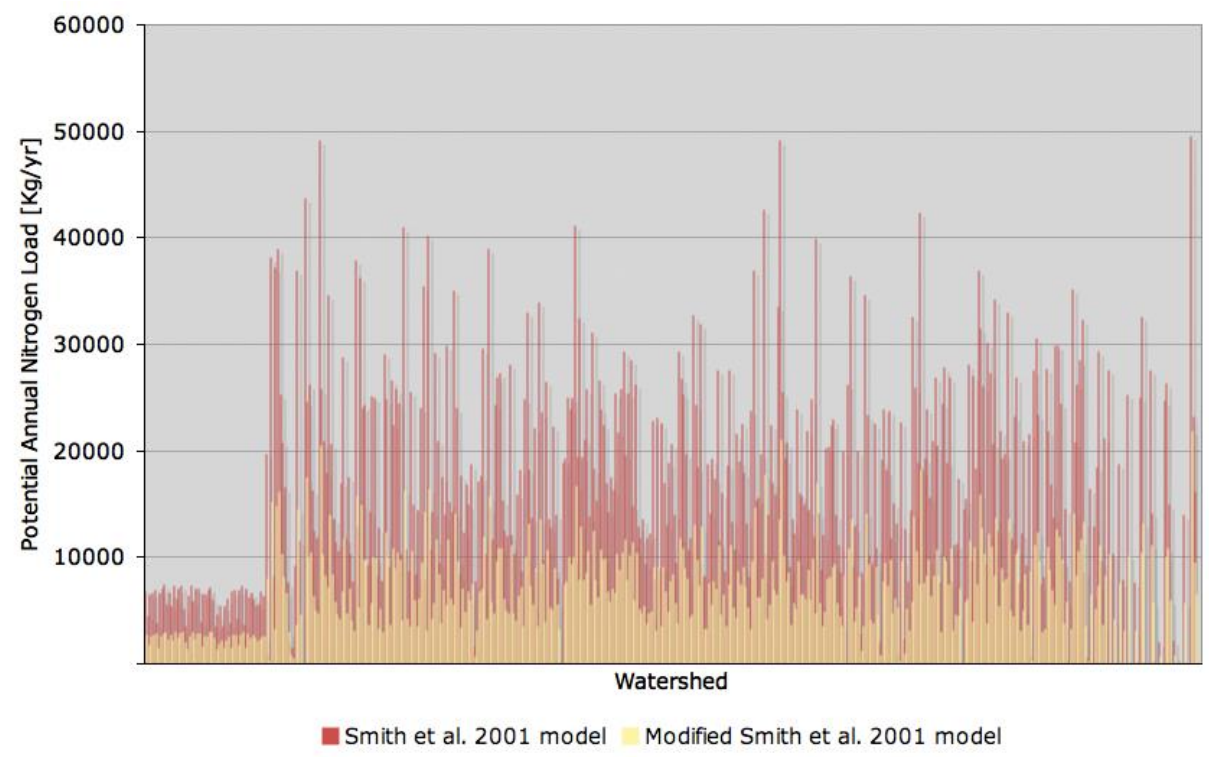

\section{REFERENCES}

Anderson, J.R., Hardy, E.E., Roach, J.T., and R.E. Witmer, (1976). A land use and land cover classification system for use with remote sensor data. Geological survey professional paper 964, U.S. Geological Survey, Washington, D.C.

Beaulac, Michael N. \& Kenneth H. Reckhow, (1982). An examination of land use - nutrient export relationships. Water Resources Bulletin, 18(6):1023-1024, December 1982.

Bondelid, T., Murray, B., Pattanayak, S., Lawrence, D., Yang, Jui-Chen, McCail, B. and D. Gilling, (2001). Water benefits and co-benefits of greenhouse gas reduction incentives in agriculture and forestry. Contract 68-01-001, EPA, 2001.

Dorn, T., (2011, August). Nitrogen sources, Retrieved August 2011, from: URL http://lancaster.unl.edu/ag/ factsheets/288.pdf.

The Camdus Group, (1998). Watershed assessment: Reading, Pennsylvania. Contract 68-C5-0061, U.S. Environmental Protection Agency, 1998.

Yetunde Jeje, (2006). Export Coefficients for Total Phosphorus, Total Nitrogen and Total Suspended Solids in the Southern Ablerta Region: A Literature Review. Regional Environmental Management, Alberta Environment, $3^{\text {rd }}$ Floor, Deerfoot Square, $2938-11$ Street N.E. Calgary, Alberta T2E7L7, 2006.

Jennings, D.B., Jarnigan, S.T. and D.W. Ebert, (2004). A modeling approach for estimating watershed impervious surface area from national land cover data. Photogrammetric Engineering and Remote Sensing, 70(11):1295-1307, 2004.

Jones, K.B., Neale, A.C., Nash, M.S., Van Remortel, R.D., Wickham, J.D., Ritters, K.H. and R.V. O’Neill, (2001). Predicting nutrient and sediment loadings to streams form landscape 
metrics: A multiple watershed study from the United States mid-Atlantic region. Landscape Ecology, 16:301-312, 2001

Kaushal, S.S., Pace, M.L., Groffman, P.M., Band, L.E., Belt, K.T., Mayer, P.M. and C. Welty, (2010). Land use and climate variability amplify contaminant pulses. Eos, Transactions, American Geophysical Union, 91(25):221-222, July 2010.

MDEQ, (2001). Draft nutrient management plan to total maximum daily load for Flathead Lake, Montana. Technical report, Montana Department of Environmental Quality, 2001.

S.C. Department of Health and Environmental Control, (1980). R.61-68, Water Classifications \& Standards. Bureau of Water, 2600 Bull Street, April 2008.

Reckhow, K.H., Beaulac, M.N., and J. Simpson, (1980). Modeling Phosphorus Loading and Lake Response Under Uncertainty: A Manual and Compilation of Export Coefficients. EPA, 440/5-08-011 edition, 1980.

Smith, J.H., Wickham, J.D., Norton, D.J., Wade, T.G. and K.B. Jones, (2001). Utilization of landscape indicators to model potential pathogen impaired waters. Journal of the American Water Resources Association, 37:1-10, 2001.

Spivey, A., (2011). Multiple Scale Landscape Pattern Index Interpretation for the Persistent Monitoring of Land-Cover and Land-Use. Ph.D., Rochester Institute of Technology, 54 Lomb Memorial Drive, May 2011.

Spivey, A. and A., Vodacek, (2017). Evaluation of multiple scale Fourier landscape pattern indices: Relevance of Fourier landscape indicators to predict fecal coliform. In Review, 2017.

USEPA, (1976). Areawide assessment procedures. Technical Report EPA-600/9-76-014, Municipal Environmental Research Laboratory, 1976.

USEPA, (2002). Polluted runoff (nonpoint source pollution). National Management Measures to Control Nonpoint Source Pollution from Agriculture, page 314, 2002.

Vogelmann, J.E., Sohl, T., Cambell, P.V. and D.M. Shaw, (1998a). Regional land cover characterization using landsat thematic mapper data and ancillary data sources. Environmental Monitoring and Assessment, 51: 415-428, 1998a.

Vogelman, J.E., Sohl, T. and Howard S.M., (1998b). Regional characterization of land cover using multiple sources of data. Photogrammetric Engineering and Remote Sensing, 64(1):45-47, 1998b.

Vogelmann, J.E., Howard S.M., Yang, L., Larson, C.R., Wylie, B.K. and N. Van Driel, (2001). Completion of the 1990s national land cover data set for the conterminous united states from landsat thematic mapper data and ancillary data sources. Photogrammetric Engineering and Remote Sensing, 67:650-662, 2001.

Wickham, J.D., Ritters, K.H., O’Neill, R.V., Reckhow, K.H., Wade, T.G. and K.B. Jones, (2000). Land cover as a framework for assessing risk of water pollution. Journal of American Water Resources Association, 36(6):1-6, 2000.

Zhu, Z., Yang, L., Stehman, S. and R. Czaplewski, (2000). Designing an accuracy assessment for USGS regional and land cover mapping program. Photogrammetric Engineering and Remote Sensing, 66(12):1425-1435, December 2000.

\section{Web adress:}

Environmental Protection Agency multi-resolution land characteristics consortium, Retrieved April, 2009, from: URL http://www.epa.gov/mrlc/. 
Spivey A., Vodacek A.: Fourier Landscape Pattern Indices for Predicting South Carolina Watershed Fecal Coliform

United States Geospatial Survey national hydrography dataset, Retrieved February 2009, from: URL http://nhd.usgs.gov.

South Carolina Department of Health and Environmental Control, Retrieved April 2009, from: URL http://www.scdhec.gov/environment/water/tmdl/.

Environmental Protection Agency multi-resolution land characteristics consortium FAQ, Retrieved July 2010, from: URL http://www.mrlc.gov/faq.php.

Surface water quality - indicator description, Retrieved July 2010, from URL http://www.envcomm.act.gov.au/soe/soe2004/Ind/surfacewaterquality.htm. 